\title{
POR UMA PEDAGOGIA DA CRIAÇÃO COM O CINEMA BRASILEIRO: CURADORIA E EXPANSÃO DO REPERTÓRIO
}

\author{
LANGIE, Cíntia* \\ RODRIGUES, Carla Gonçalves**
}

\begin{abstract}
RESUMO
A proposta deste texto é analisar as potencialidades de uma curadoria diversificada no que se refere ao audiovisual, dentro do campo da educação na contemporaneidade. Partindo de uma inquietação inicial - o pouco acesso da população brasileira aos filmes independentes realizados no país -, o artigo busca compartilhar algumas possibilidades de expansão do repertório, a partir de uma pedagogia da criação (BERGALA, 2008) com o filme brasileiro independente contemporâneo. Busca-se enriquecer o debate com as teorizações de Deleuze e Guattari (1988-2016) a respeito da força do encontro com a arte para o movimento do pensamento. A justificativa que move este estudo baseia-se no fato de que o conhecimento que se tem a respeito das obras audiovisuais não pode vir somente da mídia de massa, visto que esta impõe certo padrão estético por conta de uma política financeira de mercado. Como resultado parcial da pesquisa, defende-se que o trabalho de curadoria que busca vasculhar o panorama audiovisual para encontrar filmes que tragam alguma disrupção com o senso comum, para além do que já é ofertado na mídia hegemônica, valorizando obras brasileiras relevantes, de valor artístico e cultural, pode desencadear experiências estéticas e educativas, que ultrapassa qualquer modelo de escolarização instituído.
\end{abstract}

PALAVRAS-CHAVE: cinema brasileiro. Curadoria. Currículo. Repertório. Pedagogia da criação.

\footnotetext{
* Doutoranda em Educação pela Universidade Federal de Pelotas (UFPel), Mestre em Comunicação Social pela Pontifícia Universidade Católica do Rio Grande do Sul (PUCRS), Graduada em Jornalismo pela PUCRS. Professora adjunta do curso de Cinema e Audiovisual da UFPel. Realizadora Audiovisual e curadora do Cine UFPel. E-mail: cintialangie@gmail.com.

** Doutora em Educação pela UFRGS, Mestre em Educação pela UFPel, Graduada em Psicologia pela Universidade Católica de Pelotas (UCPel). Professora associada da FaE/UFPel, docente permanente do PPGE da UFPel. E-mail: cgrm@ufpel.edu.br.
} 


\title{
FOR A PEDAGOGY OF CREATION WITH THE BRAZILIAN CINEMA: CURATORSHIP AND EXPANSION OF THE REPERTOIRE
}

\author{
LANGIE, Cíntia* \\ RODRIGUES, Carla Gonçalves ${ }^{* * *}$
}

\begin{abstract}
The proposal of this text is to analyze the potentialities of a diversified curatorship of the audio-visual in the field of contemporary education. Starting from an initial uneasiness - the lack of access of the Brazilian population to the independent films made in the country - the paper seeks to share some possibilities of expansion of the repertoire, based on a pedagogy of creation (BERGALA, 2008) with contemporary Brazilian independent film. We seek to enrich the debate with the theorizations of Deleuze and Guattari (1988-2016) regarding the strength of the encounter with art for the movement of thought. The justification for this study is based on believing that the knowledge about audio-visual pieces cannot come only from mass media, since it imposes a certain aesthetic standard due to a market financial policy. As a partial result of the research, we defend that the curatorial work that searches the audiovisual panorama to find films that bring some disruption with common sense in addition to what is already offered in the hegemonic media, valuing relevant Brazilian works of artistic and cultural relevance, can trigger aesthetic and educational experiences, which surpasses any model of instituted schooling.
\end{abstract}

KEYWORDS: Brazilian cinema. Curatorship. Curriculum. Repertoire. Pedagogy of creation.

\footnotetext{
* PhD student in Education at UFPel, Master in Social Communication from PUCRS, Graduated in Journalism from PUCRS. Professor of Cinema and Audiovisual at UFPel. Audiovisual Director and curator of UFPel Cinema. E-mail: cintialangie@gmail.com.

** PhD in Education from UFRGS, Master in Education from UFPel, Graduate in Psychology from UCPel. Associate Professor at FaE / UFPel, permanent professor at the PPGE at UFPel. E-mail: cgrm@ufpel.edu.br.
} 


\section{DA PROPOSTA}

O presente artigo parte de uma inquietação inicial: a fragilidade das relações entre o filme brasileiro e seu público. Existe, aí, um problema e uma motivação para investigar: um disparo. Se uma pesquisa sempre nasce de um estranhamento, trata-se, nesse caso, da constatação de um certo colonialismo cultural e das dificuldades do acesso à produção cinematográfica independente brasileira por parte do espectador.

Como dizia, em meados do século passado, um dos mais importantes pensadores do nosso cinema - Paulo Emílio Sales Gomes - no Brasil, um filme para ser considerado deve vir de fora: "O público brasileiro adotou inteiramente os heróis, os temas, os sentimentos e as paisagens do filme importado" (GOMES, 2016, p. 62). Ainda hoje, podemos afirmar que continuamos na mesma condição colonial no que se refere ao consumo de filmes. Segundo dados da Agência Nacional do Cinema (ANCINE) - referentes ao primeiro semestre de 2016, os filmes estrangeiros representam $91,8 \%$ dos ingressos vendidos em salas comerciais do Brasil, enquanto os filmes nacionais ficam com $8,2 \%$ do público que vai às salas ${ }^{1}$.

Buscamos, aqui, desenvolver essa problemática a partir do campo da educação, procurando destacar a expansão do repertório audiovisual como dispositivo de resgate da cultura brasileira e a importância da curadoria nesse processo. Para dar conta de tal desafio, elegemos como ferramenta conceitual para o debate a noção de pedagogia da criação, de Bergala (2008), e a ideia de arte como potência para o movimento do pensamento, a partir das teorizações de Deleuze e Guattari (1988-2016). Além disso, investimos em um breve panorama do cinema produzido no país nos últimos anos, reunindo algumas características da produção contemporânea que envolvem questões estéticas e políticas.

A premissa que move o estudo baseia-se no fato de que o conhecimento que se tem a respeito das obras audiovisuais não pode vir somente da mídia de massa, visto que ela impõe certo padrão estético por conta de uma política financeira de mercado. Pensando em outras e variadas maneiras de arejar as ofertas de imagens na contemporaneidade, optamos, por aqui, elevar o papel da curadoria em iniciativas educacionais ou de difusão cultural, seja em escolas, instituições de bairro, salas alternativas de cinema, cineclubes ou qualquer espaço em que pessoas se reúnam para assistir a filmes. 
Nossa principal provocação é fazer com que os sujeitos que estão à frente das escolhas do que exibir, no papel de curadores, possam procurar filmes para além do que a propaganda hegemônica oferece, criando um repertório variado e, quiçá, oferecendo o cinema produzido no próprio Brasil, ainda tão desconhecido dos brasileiros. Assim, se efetuaria, por sorte, uma certa descolonização no terreno micropolítico (GUATTARI; ROLNIK, 2011). Nesse sentido, a curadoria pode ser uma espécie de vazamento, que não nega o que há de hegemônico, mas busca criar linhas de fuga ao ampliar os horizontes daqueles que ali estão envolvidos.

Variar o consumo audiovisual a fim de arejar a oferta de filmes, seja em escolas, em iniciativas de difusão cultural ou até mesmo pelo Facebook, pode ser uma forma de produzir diferença, um modo de atualizar o recipiente de matérias e ampliar o arsenal de referências, que não apenas aquelas da mídia de massa, normalmente de puro entretenimento. Essa diferença produz atravessamentos nos processos subjetivos que nos compõem como máquinas de transformação constante. É como Suely Rolnik consegue assim descrever:

O motor do desejo em suas ações pensantes é a vontade de conservação não das formas vigentes, mas da própria vida em sua essência, o que depende de negociar com as formas vigentes na superfície do mundo, de modo a encontrar os pontos onde perfurá-la para neles inscrever os cortes da força instituinte (ROLNIK, 2017, p. 12).

O encontro com uma imagem que marca, com um filme que produz diferença, pode transformar algo no sujeito, pois se configura como um processo subjetivo singular, potente. No entanto, de certo modo, talvez isso não ocorra de forma espontânea; portanto, iniciativas que estimulem encontros com o cinema como arte, na escola, podem contribuir para a proliferação de espectadores mais abertos, mais curiosos; enfim, mais orientados por uma ética do desejo singular, diferente do consumo de fácil acesso. É aí que habita a emergência da relação potente entre curadoria e educação.

\section{POR UMA PEDAGOGIA DA CRIAÇÃO COM O CINEMA}

Para tramar o cinema na educação, torna-se urgente sair do clichê de que filmes devem ser usados unicamente para transmissão de conteúdos, como recurso facilitador do ensino-aprendizagem. Inúmeras outras possibilidades para a relação do cinema com a 
educação surgem em diversas pesquisas no Brasil e no mundo (BERGALA, 2008; MIGLIORIN, 2015; FRESQUET, 2013). Talvez o grande divisor de águas nessa questão de como enxergar o cinema, dentro da educação, tenha sido Alain Bergala.

Convidado pelo governo francês para desenvolver um projeto de educação artística e de ação cultural nas escolas, Bergala desenvolveu A hipótese-cinema: pequeno tratado de transmissão do cinema dentro e fora da escola, publicado em 2002, em Paris. O livro, que ganhou edição brasileira em 2008, hoje é referência central para os estudiosos do cinema e da educação. $\mathrm{O}$ autor, que vinha pensando já há certo tempo na viabilidade de integrar arte e educação, fala da necessidade de superar a tradição de valer-se de filmes nas escolas como recurso meramente pedagógico.

A partir dessa perspectiva, o cinema, como arte, deveria integrar o conhecimento que é transmitido pela escola, mas como um "outro", trazendo uma experiência à parte da própria escola, uma experiência artística de alteridade. "A causa primeira de todos os perigos é com frequência o medo (legítimo) dos professores que nunca receberam uma formação específica nessa área e que se apegam a atalhos pedagógicos tranquilizadores, mas que, com certeza, traem o cinema" (BERGALA, 2008, p. 27). Dito de outro modo, para ele, o filme não deve ser introduzido como mais um conteúdo escolar, mas, sim, como arte, fugindo dos clichês da escolarização e das normas de como proceder. Isso significa deixar fluir o encontro dos estudantes com a alteridade, sem prescrever sensações ou significações que devam derivar do contato com a obra.

A arte não se ensina, diz Bergala (2008), mas se experimenta. Assim, o cinema pode destituir a exclusividade do saber docente. Não há a figura do professor na frente da sala que deva explicar o filme ou a cena. O professor e os estudantes articulam, juntos, o que cada cena ou cada filme pode engendrar. É pela experiência com o comum - o filme - que o professor pode sair do lugar daquele que ensina, para vivenciar a obra, e não querer decifrála, interpretá-la. Se um dos vícios da educação é fazer alunos buscarem respostas exatas, o cinema na escola pode entrar como um outro que não traz soluções, mas novas questões e novos problemas.

Segundo Deleuze, em entrevista para Claire Parnet no Abecedário (1997), há uma diferença entre questão e interrogação. A mídia de massa só atua no nível da interrogação, ou seja, se resume a perguntas banais que desencadeiam uma enxurrada de opiniões. "É por isso $======$ 
que a TV não é muito interessante, é a opinião das pessoas" (DELEUZE; PARNET, 1997, p. 87). Já uma questão coloca um novo problema, é uma pergunta que permite que o espectador coloque algo no lugar de outra coisa que antes havia neste determinado local. Aí está um outro critério possível para guiar uma curadoria singular: buscar filmes em que a problematização esteja na imagem e na linguagem, selecionando obras que não apenas tragam interrogações banais, mas que possam suscitar questões complexas, contemporâneas e relevantes.

A possibilidade de abertura de novos problemas não está somente nas temáticas dos filmes, mas na própria linguagem audiovisual. Bergala insiste em uma pedagogia da criação, isto é, acostumar os alunos a vivenciarem as sensações próprias da criação - as cores, os planos, os cortes, os sons, as expressões, os ritmos - para além de querer somente capturar a mensagem do filme. Isso pressupõe uma educação para espectadores sensíveis: evitar a busca pelo que a cena possa querer dizer, pela interpretação da palavra, mas se deixar levar pelo gesto criativo dos realizadores naquilo que é produzido no experimentador da referida arte.

Talvez fosse preciso começar a pensar - mas não é fácil do ponto de vista pedagógico - o filme não como objeto, mas como marca final de um processo criativo como arte. Pensar o filme como a marca de um gesto de criação. Não como um objeto de leitura, descodificável, mas, cada plano, como a pincelada do pintor pela qual se pode compreender um pouco seu processo de criação. Trata-se de duas perspectivas bastante diferentes (BERGALA, 2008, p. 33-34).

No encontro entre olhar e filme, o espectador pode atentar para a composição que ali está, para o gesto criativo. Desse modo, entender o mundo com o cinema é entrar em uma relação com o outro, e essa relação é da ordem da experiência, uma experimentação pessoal e coletiva, ao mesmo tempo. "Experimentar, nesse caso, é se deixar afetar e produzir com o que ainda não conhecemos e que porta o risco de trazer microdesestabilizações naquilo que entendemos como "nosso mundo" (MIGLIORIN, 2015, p. 51). O cinema, assim, funciona como abertura para que sujeitos se engajem em mundos desconhecidos, colocando em marcha processos subjetivos, o que Cezar Migliorin chama de invenção com a diferença, que pode implicar em transformações do eu e da comunidade.

Confiamos ao cinema duas possibilidades de experiência, com a própria criação e com a diferença - experiências que andam juntas. Entendemos que essas experiências estão diretamente ligadas às transformações subjetivas de professores e estudantes, transformações essas que afetam a comunidade 
como um todo (MIGLIORIN, 2015, p. 64).

O cinema permite uma experiência intensa pela sua particularidade de operar com o real. O que vemos na tela existe - foi gravado em algum lugar, em algum tempo - e o que vemos está construído, editado, trabalhado pela equipe do filme. O cinema é, portanto, realidade e ficção, e essa coexistência faz da fruição uma experiência estética singular. "Na minha poltrona, sou uma dupla testemunha: do que acontece na imagem, do que acontece em mim. O espectador de um filme é um voyeur de si"2. Pensar sobre nossa própria experiência ao ver um filme e dar sentido a ela é também da ordem da criação, já que "não há passagem ideal entre o que um filme quer dizer e a experiência que se faz com esse filme" (MIGLIORIN, 2015, p. 37). O cinema não chega sem riscos e a imagem demanda a presença de quem vê. Muitas vezes, o que se aprende com um filme é criar sentidos junto às imagens e aos sons, daí uma das forças do cinema para a educação.

De certo modo, é possível dizer que alguns filmes possibilitam uma "maior" liberdade criativa frente ao que é mostrado. Já outros - aqueles de entretenimento, mais explicativos costumam entregar todas as respostas ao público. Os que deixam espaços vazios - note-se que não estamos aqui falando de filmes enigmáticos demais, mas, sim, de obras que podem ser artísticas e comunicativas, ao mesmo tempo - permitem que o espectador se envolva de um modo diferente, já que não seguem uma lógica explicativa e de causalidade extrema. Nesse sentido, uma curadoria que procure por esse segundo tipo de filme, que é menos comum nas salas comerciais e na televisão, contribuiria para a diversificação do repertório, tanto de crianças e adolescentes, como dos próprios professores.

Ao programar filmes para estudantes ou para a comunidade em geral, ensina Bergala, não se deve subestimar o gosto dessas pessoas. Professores e curadores não precisam partir daquela ideia viciada de que "eles não gostam disso", já que o que se constitui como "o que as pessoas gostam" se cria a partir de um bombardeio cotidiano da publicidade na mídia de massa. "Hoje, em matéria de cinema, o público jovem é antes de tudo um alvo para os negociantes de filmes e produtos derivados que não têm a menor preocupação nem respeito pela formação do gosto das crianças" (BERGALA, 2008, p. 97).

A pesquisadora Adriana Fresquet (2013) lembra que, ainda hoje, as crianças passam infinitas horas por dia assistindo à TV, acostumadas a ingerir "[...] sopas televisuais, que aos 
poucos anestesiariam sua capacidade de se mexer, a vontade de explorar e buscar outras coisas para fazer" (FRESQUET, 2013, p. 25). O gosto trata-se de uma disposição que pode se formar lentamente, pouco a pouco, por imersão e experimentação, em ambientes em que existam obras de arte cinematográfica e nos quais estas sejam valorizadas como objeto de fruição. Desse modo, torna-se sempre preciso favorecer, por meio de políticas públicas e educacionais, o acesso permanente a obras cinematográficas reconhecidas como de qualidade, garantindo diversidade estética, narrativa, geográfica e cultural. E, para muitos jovens e crianças, é na escola ou em espaços alternativos que poderão ter algum contato com filmes não-hegemônicos, sobretudo os brasileiros.

\section{O FILME BRASILEIRO INDEPENDENTE}

Estamos em Nova Iorque. Uma jovem de aproximadamente 18 anos sorri, sentada em uma sala grande, dando uma entrevista. Ela fala em inglês. Percebemos que se trata de um teste de atores. Cena de um vídeo antigo, imagem de arquivo, gravado na década de 1990. A entrevistadora pergunta por que a jovem saiu do Brasil. Ela diz que no seu país as oportunidades são poucas: ou o ator faz teatro, e vive com grande dificuldade; ou trabalha em novela, o que ela não gostaria de fazer. A pessoa então questiona: "E o que você quer fazer?". A jovem diz que seu sonho é atuar no cinema, mas que no Brasil não há produção: "Lá se faz um filme por ano, no máximo". Corta.

Essa é uma cena do documentário Elena (Petra Costa, 2012), obra em que a diretora faz um mergulho pessoal em seu próprio passado, buscando entender a morte da irmã para conhecer a si própria. Elena queria ser atriz de cinema nos Estados Unidos. Petra, sua irmã 14 anos mais nova, virou atriz e cineasta brasileira. O que separa as duas? Em que diferem os anos de 1990 da segunda década dos anos 2000? Se na época de Elena trabalhar em um filme nacional era quase impossível, hoje, pouco mais de 20 anos depois, acompanha-se uma profusão de realizadores e suas obras, com uma diversidade de estilos e histórias, oriundos de diferentes regiões do país.

Em 2015, foram registrados 129 filmes brasileiros lançados em salas comerciais do país. Em 2016, foram $143^{3}$, isso contando apenas os longas-metragens. Se considerarmos a confecção de outros produtos audiovisuais, como séries, curtas, conteúdos para TV e internet, 
fica evidente que a produção não é mais o principal problema do audiovisual brasileiro. São produzidos filmes para todos os gostos e idades, sobre inúmeros aspectos desse país com dimensões continentais.

Essa profusão é possibilitada por dois motivos principais: o barateamento da produção devido à revolução digital e as mudanças profundas nas relações entre Estado e cinema, que resultou da solidificação das políticas públicas para o setor audiovisual. A criação do Fundo Setorial do Audiovisual (FSA) ${ }^{4}$ é considerada um marco na política pública de fomento, por ser determinante para o desenvolvimento de toda a cadeia produtiva do audiovisual. De acordo com Manoel Rangel, presidente da ANCINE de 2005 a 2017, a distribuição dos investimentos do FSA ficou mais equilibrada entre as regiões do país após o lançamento, em 2014, do Programa Brasil de todas as telas. O FSA trouxe novas fórmulas de incentivo a todas as cadeias desse mercado, contemplando os mais variados segmentos, desde o incentivo ao desenvolvimento de talentos e desenvolvimento inicial de projetos, até mesmo a própria produção e posterior distribuição e exibição de obras audiovisuais.

Outro fator importante nesse novo cenário é o cada vez maior número de escolas e cursos de cinema. De acordo com a publicação Cadernos do Forcine - Fórum Brasileiro de Ensino de Cinema e Audiovisual (2014), o primeiro curso de graduação em cinema em uma universidade pública no Brasil surgiu na Universidade de Brasília, em 1962. Hoje, existem 89 cursos ativos de graduação em universidades com o nome "cinema e/ou audiovisual", segundo a base do e- $\mathrm{Mec}^{5}$, sistema de controle do Ministério da Educação (MEC). Proliferam-se também oficinas de cinema em escolas, Organizações não Governamentais (ONGs), associações de bairros, casas de cultura. Propaga-se, ainda, uma onda de tutoriais na internet, que ensinam todas as etapas para fazer filmes.

Ao mesmo tempo, estão postas as condições para surgirem cada vez mais espaços qualificados de curadoria e discussão, tais como cineclubes e ações alternativas de disseminação da cultura cinematográfica. Aumentam consideravelmente, também, as pesquisas na área do audiovisual. Por exemplo, só no XX congresso da Sociedade Brasileira de Estudos de Cinema e Audiovisual (SOCINE), em 2016, havia mais de 470 pessoas apresentando trabalhos nessa área.

Então, se há pesquisas, escolas, cursos, tutoriais, espaços qualificados de discussão, políticas públicas cada vez mais solidificadas, produção audiovisual oriunda de diversas 
regiões do país: como ainda há desconhecimento desse cinema pela vasta maioria da população brasileira?

Apesar de o fator mais indicado para explicar tal situação ser o oligopólio estrangeiro que dificulta o acesso, ainda se verifica um certo preconceito frente às obras brasileiras, possivelmente atrelado à época das pornochanchadas durante a ditadura militar na década de 1970. De acordo com a pesquisadora Cláudia Mogadouro (2015), o preconceito vem do desconhecimento.

Tenho insistido com professores para saber sobre sua familiaridade com o nosso cinema. A resposta é o que já se esperava: apenas uma minoria dos professores conhece o cinema brasileiro. E, como o preconceito nasce justamente do desconhecimento, grande parte assume que "não vê, porque só tem pornochanchada, palavrão e violência". Curiosamente, o termo "pornochanchada" vem na fala até de professores jovens, que não vivenciaram os anos 1970/80, quando realmente eram exibidos muitos filmes eróticos, alguns de qualidade bem questionável. O que mostra que se trata de um imaginário e não necessariamente de uma experiência (MOGADOURO, 2015, n. p.).

Essa legenda negativa do cinema nacional pode ter sido gerada, também, por questões técnicas, sobretudo de qualidade do áudio, em uma época em que os equipamentos de captação eram caros e difíceis de operar. Contudo, falando-se em termos atuais, é evidente que essa legenda é uma redução e não condiz com o cinema brasileiro produzido na última década. De 2011 a 2016, foram lançados em salas comerciais 698 longas-metragens nacionais, de acordo com a ANCINE. Fora isso, há tantos outros que são produzidos e que não conseguem estrear em salas, ficando restritos a festivais, espaços alternativos ou à internet. Obras, pois, que poucas pessoas conhecem.

O pesquisador Jean-Claude Bernardet declara que, nos dias de hoje, grande parte dos filmes brasileiros relevantes em nível da evolução da linguagem cinematográfica, são irrelevantes em nível de público, havendo um verdadeiro "divórcio" entre a produção e a sociedade brasileira. Essa inquietação de Bernardet foi materializada no artigo de Pinto (2013), intitulado Cinema irrelevante: uma análise do cinema nacional contemporâneo a partir das percepções do crítico Jean-Claude Bernardet. Sua principal inquietação está na pergunta: é político um cinema que não tem público?

Para ele, a falta de interesse do público frequentador das salas de shoppings centers pelos filmes nacionais advém da dificuldade de compreensão da narrativa. "Talvez se o 
espectador tiver maior contato com a arquitetura do cinema, os filmes com investigação de linguagem - os irrelevantes - possam ser compreendidos por um público mais amplo" (PINTO, 2013, n.p.). Novamente, aqui, está latente que o problema se centra no (não) acesso da população às obras cinematográficas brasileiras e é por esse motivo que trazemos para o centro do debate o trabalho de curadoria nas instituições de ensino que vise formar, desde cedo, por meio de uma pedagogia da criação, sujeitos atentos ao cinema de seu país.

Tanto Bernardet (1967) como Gomes (2016), citado na abertura deste artigo, apontam uma ética colonizada como característica de um país de mentalidade importadora. Para algo ser bom, ainda hoje, parece que precisa vir de fora. Só que, segundo esses estudiosos do cinema brasileiro, o filme nacional é sempre uma outra experiência e aqui reside a premissa fundamental da investigação deste artigo. "O filme nacional tem outro efeito. Ele é oriundo da própria realidade social, humana, geográfica, etc., em que vive o espectador [...], o filme nacional tem sobre o público um poder de impacto que o estrangeiro não costuma ter" (BERNARDET, 1976, p. 21). Em uma sessão de filme brasileiro, aquilo que acontece na tela espelha uma realidade comum ao próprio espectador: inquietações, pensamentos, modos de vida. Não haveria, aí, um outro componente de peso para a urgência da diversificação do repertório em escolas e iniciativas de difusão cultural?

\section{AS POTENCIALIDADES DA DIVERSIFICAÇÃO DO REPERTÓRIO NA EDUCAÇÃ̃O}

O que estamos procurando ressaltar com este texto é a ideia de que o repertório é crucial no campo da educação, já que a concentração das ofertas se fecha cada vez mais em pequenos grupos estrangeiros e, pois, se torna ainda mais necessária a atitude de ir além do que está posto, do que está dado, do que está ao alcance da visão. Se o hegemônico no campo audiovisual são filmes do mercado, lançados pelos grandes estúdios - majoritariamente hollywoodianos -, com grandes campanhas de marketing, visando apenas ao retorno de bilheteria, uma curadoria que flexibiliza essa lógica pode tornar-se, pois, educativa. Haveria, então, uma força política na atitude de vasculhar filmes fora do circuito, obras brasileiras, de estilos e temáticas distintos: filmes relevantes, com valor artístico e cultural. Existe, pois, conexão direta entre o trabalho de curadoria e o espectador. 
A palavra curadoria tem origem epistemológica na expressão que vem do latim curator, que significa tutor, ou seja, aquele que tem uma administração a seu cuidado, sob sua responsabilidade. Professor-curador seria, então, aquele que vasculha, que intervém na ordem do discurso, ao expandir o universo de obras disponíveis. "A necessidade de uma intervenção intencional é fundamental para um projeto que vise abalar o padrão ético e estético dominante no campo artístico-cultural, de forma geral, e do cinema em particular" (LOUREIRO, 2008, p. 148). É a ideia de uma pedagogia da criação com o filme brasileiro que insiste no potencial criativo das obras, no gesto, pensando na formação estética e política dos espectadores. Ser um curador, portanto, é expandir horizontes, tanto na arte como na educação.

Na última Reunião Científica da Associação Nacional de Pós-Graduação e Pesquisa em Educação - ANPED (2017), em São Luís do Maranhão, a pesquisadora Adriana Fresquet (UFRJ) apresentou o vídeo Abecedário com Jorge Larrosa Bondía ${ }^{6}$, em presença do próprio pesquisador espanhol. No vídeo, Larrosa fala da noção de professor elegante: elegante é aquele que seleciona. Selecionar, eleger: escolher coisas singulares para compartilhar. Segundo o pesquisador, a elegância do professor materializa-se na opção por matérias relevantes. No caso específico do audiovisual, ressalta ele, seria necessário que os professores amassem o cinema, buscando assistir aos mais variados filmes, deixando-se levar pelo gesto criativo de cineastas desconhecidos e por obras que fogem ao padrão de mercado. A tarefa do professor-curador é, pois, inicialmente, um trabalho consigo mesmo.

Para Rolnik (2017), poderíamos dividir a figura do curador em dois: curador-que-cria e curador-criativo. Enquanto o primeiro seria aquele que segue uma bússola ética, dando escuta aos afetos que o cercam, o segundo submete-se aos interesses do capital e ao inconsciente colonial e atua produzindo réplicas do repertório existente. A própria autora fala da impossibilidade de haver uma divisão estanque entre esses dois polos, e que tais figuras não existem em estado puro. Essa dualidade é um artifício que nos permite entender as forças em jogo no campo das práticas curatoriais. Isso posto, o trabalho do curador-que-cria é assim por ela definido:

O que move o curador-que-cria depende de um constante trabalho consigo mesmo, o qual consiste em resistir ao poder do inconsciente colonialcapitalístico em sua própria subjetividade. Isto não se alcança por meio de um aprendizado teórico ou ideológico, tampouco pela conscientização dos 
embates macropolíticos ou pela mera boa vontade. Trata-se de um trabalho sutil e complexo que implica em manter seu próprio corpo vulnerável às forças ambientes e em estar à escuta dos afetos que delas resultam em sua experiência fora-do-sujeito (ROLNIK, 2017, p. 18-19).

No universo brasileiro, o trabalho sutil de vasculhar e procurar filmes pode ocorrer de diferentes formas, seja por meio de busca em sites de iniciativas alternativas de projeção, como cineclubes e salas universitárias ${ }^{7}$, seja por meio de participação em festivais de cinema. É interessante, ainda, conhecer alguns portais do cinema brasileiro, como o site da $\mathrm{ANCINE}^{8}$, ou ainda aproximar-se de iniciativas de difusão cultural das universidades, principalmente aquelas que possuem cursos de Cinema e Audiovisual. É possível, ainda, cadastrar-se em iniciativas de distribuição alternativa ${ }^{9}$, as quais tornam cada vez mais fácil a realização de sessões comentadas de filmes brasileiros. Existe, também, o canal Cinemateca Popular Brasileira no YouTube ${ }^{10}$, com acesso simples e fácil, que disponibiliza gratuitamente diversas obras nacionais.

Sem negar as vantagens da livre circulação da arte no universo ilimitado que é a internet, Bergala (2008) argumenta que a rede, por si só, não leva as pessoas ao encontro da arte. Abre-se um campo infinito de possibilidades, mas o que se percebe é que os internautas só buscam como desejável aquilo que é difundido pela publicidade do momento. O trabalho de curadoria, ao contrário, deveria agir para arejar as ofertas, trazer à tona o que nem sempre é de conhecimento das pessoas. E o convite que buscamos fazer, com este artigo, é que professores-curadores possam abrir-se ao repertório audiovisual brasileiro, em vias de oferecer aos estudantes, desde muito cedo, componentes da cultura de seu país, instigando uma pedagogia da criação a partir de filmes feitos em diversas regiões do Brasil.

Isso porque a expansão do repertório está diretamente ligada à produção de processos subjetivos nos espectadores. Para Guattari (1992), a subjetividade é o dentro, e o fora, o mundo em constante fricção com os corpos, os corpos como máquinas desejantes. Se segundo uma tradição filosófica o sujeito seria algo do domínio de uma suposta natureza humana, Guattari propõe uma inversão do conceito: “[...] a ideia de uma subjetividade de natureza industrial, maquínica, ou seja, essencialmente fabricada, modelada, recebida, consumida" (GUATTARI; ROLNIK, 2011, p. 33). Assim, tudo aquilo que nos atravessa, aquilo com o qual temos encontros, nos marca e nos constitui. 
Nesse sentido, podemos ampliar essa ideia de processos de subjetivação, trazendo para o debate a relação desse movimento contínuo do sujeito e do mundo com a faculdade de pensar. Como nosso viés perpassa o campo da educação, a ideia de movimento do pensamento a partir de encontros com obras de arte pode reforçar a defesa por uma curadoria mais diversificada e ousada. Antes de seus escritos sobre o cinema, Deleuze escreve sobre o pensamento, em seu livro Diferença e Repetição (1988). Para o filósofo, pensar não é reconhecer, não está atrelado à faculdade da recognição. O pensamento deveria procurar inovação em aventuras mais estranhas que aquilo que simplesmente já conhecemos e reconhecemos, pois, quando olhamos para algo e conseguimos imediatamente determiná-lo ou classificá-lo a partir de um reconhecimento, nosso pensamento não é convidado ao movimento.

O que pode tirar o pensamento da inércia é algo que o constrange, uma espécie de desmoronamento ou arrombamento. Isso pode advir do novo, "isto é, a diferença" (DELEUZE, 1988, p. 235). Isso se dá, portanto, quando entramos em contato com algo que não sabemos ainda significar. Pensar, desse modo, é criar. É traçar circuitos cerebrais inéditos, pois faz nascer aquilo que ainda não existe, de uma forma que ainda não havia sido pensada. E aí percebemos uma relação direta com a noção de pedagogia da criação de Bergala, no desejo de levar filmes não hegemônicos para a escola a fim de oportunizar que jovens e crianças criem junto aos filmes, sem a figura do professor que explica a obra, mas na possibilidade de fruição do material como gesto artístico.

Para Deleuze, certas coisas, obras ou ideias convocam um estado animal de estar à espreita, isto é, manter-se aberto para ser afetado. A isso, ele dará o nome de encontro. Um encontro é da ordem daquilo que tira o indivíduo do tempo cronológico, empurra-o para fora da maneira como vê e sente a realidade (DELEUZE; PARNET, 1997). Aquilo que nos faz pensar, nos permite, pois, um encontro, na perspectiva filosófica deleuziana. "Não acredito na cultura; acredito, de certo modo, em encontros", declara ele no Abecedário (DELEUZE; PARNET, 1997, p. 11).

Na perspectiva filosófica, o encontro, de fato, dá-se na fricção entre espectador e obra, em determinadas situações, em condições singulares e micropolíticas. É como um acontecimento que arrepia, um abalo, que tira o pensamento do seu curso tradicional. Um encontro ocorre quando a obra nos alimenta, diz algo para nós, nos apresenta novas paisagens 
de possíveis, faz saltitar as engrenagens enferrujadas, despe velhos hábitos, desmascara preconceitos e abre outras imagens em constelação.

A arte, para Deleuze e Guattari (2010), traça desvios, opera mudanças de níveis e de escala naquilo que é determinado como pensamento hegemônico. Ao explorar o processo de criação, esses autores insistem no espaço em branco, um quê de silêncio, abstração, ambiguidade, que vão chamar de vazios. "Os blocos precisam de bolsões de ar e de vazio, pois mesmo o vazio é uma sensação, toda sensação se compõe com o vazio" (DELEUZE; GUATTARI, 2010, p. 195). Assim, uma pedagogia da criação com o cinema pode acontecer quando um filme faz vir diante do público não a semelhança, mas a pura sensação.

Não se trata de buscar uma correspondência entre o que é visível, dizível e o que o público deve apreender. Ao contrário, trata-se de criar fissuras, suspensão, convocando todo corpo para agir: permitir o encontro, suscitar o pensamento. O que conta é o espaço oco entre duas imagens, esse interstício, um silêncio que obriga o pensamento a preencher a lacuna. "Um cérebro que pisca, e re-encadeia ou faz anéis, assim é o cinema" (DELEUZE, 2005, p. 256-257).

Para o cineasta iraniano Abbas Kiarostami, o cinema não poderia ter o dever de contar histórias, já que o romance pode fazer isso melhor. No cinema há o gesto, a música, o sonho, a poesia e, por isso, os filmes deveriam carregar a marca de certa incompletude, para excitar a imaginação do público. "Penso que, se queremos que o cinema seja considerado uma forma de arte maior, é preciso garantir-lhe a possibilidade de não ser entendido" (KIAROSTAMI, 2013, p. 185).

A busca do trabalho de Kiarostami, segundo ele próprio, é tentar fazer ver sem mostrar, para que cada espectador possa criar sentidos de acordo com sua própria experiência. Não é preciso dizer tudo ao espectador, insiste ele, e aqueles filmes de entretenimento que explicam demais tornam-se pornográficos. "Não deixo espaços em branco apenas para que as pessoas tenham algo para completar. Deixo-os em branco para que as pessoas possam preenchê-los de acordo com o que pensam e querem" (KIAROSTAMI, 2013, p. 187).

Assim, a proposta de uma curadoria diversificada, que investe na "elegância" de escolher filmes menos explicativos e menos recheados de clichês narrativos, deveria buscar oportunizar, na escola, experiências de distanciamento, e não acolhimento. Lembrando que, $======$ 
para isso, não importa apenas o conteúdo do filme, mas a forma-cinema - aquele componente das imagens em movimento que é capaz de nos revelar a mais alta determinação do pensamento.

\section{5 ÚLTIMOS APONTAMENTOS}

Tudo isso posto, gostaríamos de fechar esta discussão apenas retomando a força que existe nas atividades que buscam uma oxigenação do repertório audiovisual na atualidade. $\mathrm{Na}$ trama do cinema brasileiro com a educação, a curadoria apresenta-se como elemento de destaque. A força da curadoria arejada, que resiste e vasculha, encontra uma ética engajada, tão necessária a uma educação que pode ocorrer nos pequenos encontros - micropolíticos em golpes de subjetivação pelo contato com o novo, com aquilo que ainda não se sabe como significar. Uma curadoria que elege por meio de uma sensibilidade, mas também pelo conhecimento da urgência das resistências ao hegemônico, da necessidade de oportunizar experiências com matérias que não têm espaço nas janelas tradicionais de exibição.

A pluralidade dos filmes brasileiros independentes da safra atual é uma realidade ainda pouco conhecida, pouco explorada na educação. E a força de uma curadoria arejada, que investiga obras não-hegemônicas, está no fato de oferecer elementos simbólicos, imagens e sons, gestos, que permitem ao espectador brasileiro admirar sua realidade e nela se envolver, em suas diferenças, suas origens. Uma pedagogia da criação com o cinema brasileiro não só é possível, como se configura como experiência singular com obras brasileiras de relevância artística e cultural, pois podem abrir certas fissuras no mundo do espectador.

Não só uma curadoria se faz necessária, como a ampliação da visão sobre o uso de filmes em processos formativos. Superar o clichê hoje instaurado, de que filmes devem ser usados unicamente para transmissão de conteúdos, é o primeiro passo para permitir uma pedagogia da criação. A arte é uma expressão da sensação; o cinema na escola não deveria, portanto, ser pensado apenas como um instrumento, ou multiplicador de temáticas: é aula de história, vamos exibir aquele filme que fala do descobrimento do Brasil. Nem deveria ser encarado como artifício para "preencher" tempo: faltou o professor de física, então vamos 
passar um filme. A força do cinema pode estar em seu potencial artístico, permitindo diferentes processos de criação, de acordo com a vontade e o perfil de cada educador.

Por fim, o estudo sobre curadoria e educação pode ainda ensinar que o cinema brasileiro independente contemporâneo é relevante pelo gesto criativo - inovações que levam o pensamento a pensar -; pelos encontros que podem permitir - abrindo brechas para processos de subjetivação singulares -; e pela experiência de invenção de sentidos peculiares com os filmes. É isso que engendra processos formativos a partir do cinema, favorecendo um convite ao movimento do pensamento, pelo contato com obras que não necessariamente se encaixam nos padrões hegemônicos. Esse tipo de experiência, com foco artístico e não apenas temático, investe em uma abertura à diferença, o que está na ordem do dia das pesquisas contemporâneas em educação, tornando-se, pois, uma ação política - e o melhor: possível a todos nós, curadores. 


\section{REFERÊNCIAS}

BERGALA, Alain. A hipótese-cinema. Pequeno tratado de transmissão do cinema dentro e fora da escola. Tradução Mônica Costa Netto e Silvia Pimenta. Rio de Janeiro: Booklink; CINEAD-LISE/FE/UFRJ, 2008.

BERNARDET, Jean-Claude. Brasil em tempo de cinema: ensaio sobre o cinema brasileiro. 2. ed. Rio de Janeiro: Paz e Terra, 1976.

DELEUZE, Gilles. A imagem-tempo. Tradução Eloisa de Araujo Ribeiro. São Paulo: Brasiliense, 2005.

DELEUZE, Gilles. Diferença e repetição. Tradução Luiz Orlandi e Roberto Machado. Rio de Janeiro: Graal, 1988.

DELEUZE, Gilles; GUATTARI, Félix. O que é a filosofia? São Paulo: 34, 2010.

DELEUZE, Gilles; PARNET, Claire. L' Abécédaire de Gilles Deleuze. Entrevista com Gilles Deleuze. Editoração: Brasil, Ministério de Educação, "TV Escola", 2001. Paris: Editions Montparnasse, 1997. 1 videocassete, VHS, son., color.

FRESQUET, Adriana. Cinema e educação: reflexões e experiências com professores e estudantes de educação básica, dentro e "fora" da escola. Belo Horizonte: Autêntica, 2013.

GOMES, Paulo Emílio Sales. Uma situação colonial? São Paulo: Companhia das Letras, 2016.

GUATTARI, Félix. Caosmose: um novo paradigma estético. São Paulo: 34, 1992.

GUATTARI, Félix; ROLNIK, Suely. Micropolítica: cartografias do desejo. Rio de Janeiro: Vozes, 2011.

KIAROSTAMI, Abbas. Abbas Kiarostami: duas ou três coisas que sei de mim. São Paulo: Cosac Naify, 2013.

LOUREIRO, Robson. Educação, Cinema e Estética: elementos para uma reeducação do olhar. Educação \& Realidade, Porto Alegre, v. 1, n. 33, p. 135-154, 2008.

MIGLIORIN, Cezar. Inevitavelmente cinema: educação, política e mafuá. Rio de Janeiro: Beco do Azougue, 2015.

MOGADOURO, Cláudia. Educadores, por que o preconceito com o cinema brasileiro? Instituto NET, Claro e Embratel: Educação, 13 out. 2015. Disponível em: $<$ http://neteducacao.com.br/noticias/home/educadores-por-que-o-preconceito-com-o-cinemabrasileiro>. Acesso em 15 jan. 2017. 
PINTO, Ivonete. Cinema irrelevante: uma análise do cinema nacional contemporâneo a partir das percepções do crítico Jean-Claude Bernardet. ABRACCINE, 18 jun. 2013. Disponível $\mathrm{em}:<$ https://abraccine.org/2013/06/18/cinema-irrelevante-uma-analise-do-cinema-nacionala-partir-das-percepcoes-de-jean-claude-bernardet/ >. Acesso em: 25 set. 2018.

ROLNIK, Suely. O saber-do-corpo nas práticas curatoriais: driblando o inconsciente colonial-capitalístico. In: Seminário Curadoria em artes visuais: um panorama histórico e prospectivo. Santander Cultural, Porto Alegre, 18 de maio a 23 de julho de 2017. Disponível em: <https://pt.scribd.com/document/363429106/Texto-Suely-Rolnik >. Acesso em: 14 dez. 2017.

\section{FILMES CITADOS}

ELENA. Direção: Petra Costa, Brasil, 2012.

\section{NOTAS}

\footnotetext{
${ }^{1}$ Disponível em: <http://oca.ancine.gov.br/>. Acesso em: 5 out. 2016.

${ }^{2}$ Declaração de Cezar Migliorin na internet. Disponível em: <http://www.revistacinetica.com.br/30fragmentos.htm>. Acesso em: 14 set. 2016.

${ }^{3}$ Dados obtidos no Observatório do Cinema e Audiovisual (OCA) da ANCINE.

${ }^{4}$ O Fundo Setorial do Audiovisual (FSA) é um fundo destinado ao desenvolvimento articulado de toda a cadeia produtiva da atividade audiovisual no Brasil. Criado pela Lei $\mathrm{N}^{\circ} 11.437$, de 28 de dezembro de 2006, e regulamentado pelo Decreto $N^{\circ}$ 6.299, de 12 de dezembro de 2007. O FSA é uma categoria de programação específica do Fundo Nacional de Cultura (FNC).

${ }^{5}$ Informação do Forcine - Fórum Brasileiro de Ensino de Cinema e Audiovisual.

${ }^{6}$ Disponível em: <https://www.youtube.com/watch?v=5FtY1psRoS4>. Acesso em: 24 fev. 2018.

${ }^{7}$ Disponível em: <https://www.facebook.com/CINUSP>. Acesso em: 12 set. 2017; $<$ https://www.facebook.com/cineufpel>. Acesso em: 9 abr. 2018, <https://www.facebook.com/cinemetropolisufes $>$. Acesso em: 24 out. 2017.

${ }^{8}$ Disponível em: <http://ancine.gov.br>. Acesso em: 10 fev. 2018.

${ }^{9}$ Disponível em: 〈www.taturanamobi.com.br>. Acesso em: 2 dez. 2017; 〈https://www.videocamp.com/pt $>$. Acesso em: 27 out. 2017; ou para curtas <www.portacurtas.org.br>. Acesso em: 15 jan. 2018.

${ }^{10}$ Disponível em: 〈https://www.youtube.com/channel/UCEPXrSvxoAHS11_6pbdFsDQ>. Acesso em: 6 abr. 2018.
} 